\title{
Assessment of Solid Waste Management Practices and the Role of Public Participation in Jigjiga Town, Somali Regional State, Ethiopia
}

\author{
Yohanis Birhanu ${ }^{1,}$, , Genemo Berisa ${ }^{2}$ \\ ${ }^{1}$ Department of Chemistry, Jigjiga University, Jigjiga, Ethiopia \\ ${ }^{2}$ Department of Geography and Environmental Studies, Jigjiga University, Jigjiga, Ethiopia
}

Email address:

yohanisbirhanu@gmail.com (Y. Birhanu),genemo09@gmail.com (G. Berisa)

\section{To cite this article:}

Yohanis Birhanu, Genemo Berisa. Assessment of Solid Waste Management Practices and the Role of Public Participation in Jigjiga Town, Somali Regional State, Ethiopia. International Journal of Environmental Protection and Policy. Vol. 3, No. 5, 2015, pp. 153-168. doi: 10.11648/j.ijepp.20150305.16

\begin{abstract}
Solid waste, which is a consequence of day-to-day activity of human kind, needs to be managed properly. Jigjiga City, like other cities in developing countries, faces problems associated with poorly managed solid waste operation. This study concerns about analysis of the city's current municipal solid waste management problems, opportunities and existing solid waste management practices and role of community participation. The survey was conducted in 03 and 05 kebeles. Different sampling methods were employed to select the study units including: stratified sampling, systematic random sampling, and purposive sampling. Though the bulk of the data collected were qualitative in nature, it was also supported by quantitative information collected through survey and secondary sources. The study discovered that there is low performance of SWM in the city mainly due to: lack of properly designed collection system and time schedule, inadequate and malfunctioning operation equipment, open burning of refuse, poor condition of the final dumpsite and less awareness creation among community which encouraged illegal dumping are the technical problem identified. Insufficient funds as well as lack of promotion on-waste reduction, recycling, absence of waste recovery, practice of energy option, waste separation and composting are among the management challenges facing the city. Social problems encountered include: lack of public awareness, unwillingness to pay, ill dumping manner (often around residence and any open spaces) and improper outlook for waste workers. Incompetence of organizations in terms of equipment required for operation and man power /staff qualifications, training and human resource developments and/or unreliable service are the institutional challenge that the city encountered in the sector. Finally, the study forwarded some important recommendations towards improving the waste management practices.
\end{abstract}

Keywords: Solid Waste Management, Disposal System, Community Participation, Jigjiga City

\section{Introduction}

Waste was an early problem of mankind, and a growing one that is of major concern to every nation of the world (Allende 2009). In early pre-industrial times, waste generation was not an issue as populations were smaller. Waste was disposed of in the ground where it would turn to compost to improve soil fertility. Waste management issues are coming to the forefront of the global environmental agenda at an increasing frequency, as population and consumption growth result in increasing quantities of waste. In the context of the above mentioned challenge a New
Paradigm for waste management has emerged, shifting attention to resources efficiency and minimization of environmental impacts throughout the life cycle of waste management, from waste prevention to safe disposal. The primary objective of waste management is to give adequate protection to the general public and environment from harmful effects of waste.

Municipal SWM is a problem that is experienced by all counties in the world. It is an issue mostly witnessed in urban areas as a result of high surge in population growth rate and increase in per capita income thus posing a danger to environmental quality and human health (Javaheri 2006). Because of its nature, it has remained one of 
the major environmental problems man continues to face.

An investigation into waste management is now becoming increasingly critical in developing countries (Kyessi and Mwakalinga 2009). (Issam et al. 2007) report that waste management, which has generally been understudied, in developing countries is now receiving increasing attention in the literature. Municipal SWM problems have become more pronounced in recent years, as a result of inadequate collection and disposal of wastes. In most cities, wastes are not properly collected and where proper collection is ensured, only a small fraction receives proper disposals.

Urban waste management has been a challenge for municipalities and urban governments in the developing world, largely due to poor infrastructure, bureaucratic competence and limited institutional capacity of the municipalities. Municipalities throughout Ethiopia are not free of these problems as they have been facing major challenges with solid waste collection and landfill management.

According to Environmental Protection Authority (EPA) and World Bank study conducted in 2004, per capita amount of waste generated in Ethiopia ranged from 0.17 to $0.48 \mathrm{~kg} /$ person/day for urban areas to about 0.11 to 0.35 $\mathrm{kg}$ /capita/day for rural areas. The range depends on several factors such as income and season. The total generation of municipal solid waste in Ethiopia in

2003 is estimated to be 2.8 to 8.8 million tones. This can be split to approximately 0.6 to 1.8 million tons from rural areas and 2.2 to 7 million tons from urban areas (EPA/World Bank 2004).

In many of the cities in Ethiopia the municipality administration is responsible for waste collection. Though, there is a wide variation in performance in relation to waste collection in cities of Ethiopia, it has become a common business practice to have household waste to be precollected by individuals who are organized through formal or informal association. The pre- collected waste is then transferred into containers which are then collected by municipalities. Nevertheless, in many cities there are not enough containers to cover the population and vehicles are typically under maintenance or out of service for long periods of time. As there is very limited effort to recycle, reuse or recover the waste that is being generated; waste disposal has been the major mode of waste management practice. When considering SWM in general, it should be noted that it is rather small fraction of waste that ever reaches dump sites or landfills in Ethiopia. Some studies have shown that only $43 \%$ of waste is collected in the country are properly collected and disposed in open landfills. The remaining waste is indiscriminately disposed in drainage lines, open spaces, street sides or is informally burned.

According to Environmental Protection Authority and World Bank study conducted in 2004, per capita amount of waste generated in Ethiopia ranged from 0.17 to 0.48 $\mathrm{kg} / \mathrm{person} /$ day for urban areas to about 0.11 to $0.35 \mathrm{~kg} / \mathrm{capita} /$ day for rural areas. The total generation of municipal solid waste in Ethiopia in 2003 is estimated to be 2.8 to 8.8 million tones. This can be split to approximately 0.6 to 1.8 million tons from urban areas and 2.2 to 7 million tons from rural areas (EPA/World Bank 2004). Jigjiga City, being the largest city in the Somali Regional State and one of the swiftly urbanizing centers in the country, has been grappled with an increasingly growing urban waste management problem. Taking per capita amount of waste generation in the nation and total population of the city as to CSA (2007) into account, the total generation of municipal solid waste in city in 2007 is estimated to be 21.4 to 60.4 tones.

Currently only $55 \%$ of the solid waste produced per day is collected and disposed by the Hormud SWM Company in the Sheik Ali Gure dumpsite at $6 \mathrm{~km}$ away from the city center and the remaining $45 \%$ of the solid wastes are uncollected and dumped in unauthorized areas such as open fields, ditches, sewers, streets and many other available spaces in the city. Uncollected garbage is a serious environmental hazard for all, especially in areas where the roads are not accessible for collection by the collectors. These cause bad smells and attract various disease vectors and pests resulting in deteriorated aesthetic quality of the city.

The social waste collection service is unsatisfactory, and scenes of scattered waste are common in most part of the city. As a result, the population has the opinion that the municipal solid waste collection service is not functioning properly. As a result of this, the willingness of the population to cooperate with waste collection operation and to pay for the service is low. Solid waste collected from hospitals, residential and business areas is dumped at the dumpsite on the outskirt of the city with little incineration in the hospitals. In terms of social waste processing and recycling, little is done at all level of its management i.e. there is no source separation or sorting and this happens at disposal sites too. But some scavengers at dump sites practice an informal type of waste recovery. Other options like energy recovery and composting are not practiced as alternatives for waste recovery.

The disposal of waste has proved to be a major public health issue and a vital factor affecting the quality of the environment. This, especially in Ethiopian cities has become one of the most intractable environmental problems today. One of the main problems facing the city is open and indiscriminate dumping of refuse (authors, observation). Piles of decaying garbage are found in strategic locations in the heart of the city. Wastes in such places are obviously a source of air and water pollution, land contamination and environmental degradation.

\section{Literature Review}

\subsection{Solid Waste Concept}

Solid waste technically, any solid material disposed of as no longer useful in common usage the term has somewhat more limited meaning of solid materials thrown out by house holders those materials referred to by engineers as municipal 
solid waste. Solid (nonhazardous) waste is defined as any garbage, refuse, sludge from a waste treatment plant, water supply treatment plant, or air pollution control facility and other discarded material, including solid, liquid, semi liquid, or contained gaseous material resulting from industrial, commercial, mining, and agricultural operations and from community activities, but does not include solid or dissolved material in domestic sewage (Benny J. 2005). Solid wastes are wastes arise from human and animal activities, including the heterogeneous mass of garbage from the urban community as well as more homogenous accumulation comprising of countless different materials such as food wastes, packaging material such as paper, metals, plastic, glass, construction wastes, pathological wastes and hazardous wastes. Rapid population growth and urbanization in developing countries have led to the generation of enormous quantities of solid wastes and consequently environmental degradation.

\subsection{Sources and Types of Municipal Solid Waste}

In order to categorize what exactly municipal solid waste constitutes, there have been different attempts of categorization based on numerous classification criteria. Some of those criteria are source from which solid waste emanates, and nature of solid waste components. On the basis of the nature of items that constitute solid wastes, it can be classified into organic or inorganic, combustible or noncombustible, and putrescible or non-putrescible. With respect to source from which solid waste emanates, (Martin 2000) categorized municipal solid waste as household (residential) refuse, institutional wastes, street sweepings, commercial areas wastes, as well as construction and demolition debris. In developing countries, MSW also contains various amounts of industrial wastes from small scale industries. In these sources there are diverse types of solid wastes.

\subsection{Characteristics of Municipal Solid Waste}

For effective and efficient management of solid waste generated in a particular city, adequate knowledge and data about the characteristics of solid waste is essential. In order to decide or determine types of facilities required for solid waste management, best disposal options, and projecting future needs requires precise information about quantities, compositions, densities, moisture content and calorific value of solid waste produced in a city (Rushbrook 1999 in G/tsadkan 2002). Though all the above characteristics are important, for this study the researcher emphasize only on municipal SWM practices with due attention also given to the role community participation.

Solid waste generation rate: refers to the "amount of waste disposed during a given period of time and the quantification of it involves different methods: by measurement at the point of generation, through use of vehicle survey and by examination of records at the disposal facility" (UNEP 2009; cited in Zebenay 2010). The rate of solid waste generated in a given town is basically determined by demographic growth, seasonal variation, geographic location, economic development and people's attitude towards waste.

(Nashiimirimana 2004) explained the influence of economic development by comparing gross national product of developed and developing countries with their waste generation rate. The author argues that the higher the gross national product of a country result the higher the generation of waste. This means that due to difference in the level of economic performance, waste generation rate of developed countries is much greater than that of developing countries. Although developing countries have a lower rate of waste generation compared to developed countries, their quantum of waste is high owing to their higher levels of population growth and he concluded that this clearly shows impact of population size on waste generation rate. On the other hand, people's attitude towards waste can also conditioned solid waste generation rate in the form of their pattern of material use and waste handling, their interest in waste reduction and minimization, and the degree to which they refrain from indiscriminate dumping and littering (Schubeler 1996). Therefore, an accurate knowledge of quantity and rate of solid waste generation in a given area is essential for preparation and implementation of appropriate MSWM. Because it provides information on human, financial and equipment resources required for collection and transportation of waste, to enact appropriate laws on waste reduction, and establish current and future needs for solid waste disposal sites (Abel 2007).

Physical composition: refers to quantity of various material types in a particular waste stream. Just like waste generation rate, physical composition of solid waste is also extremely variable as a consequence different factors. The major once are of the following:

a) Economic level difference: higher income areas are usually producing more inorganic waste while low income areas produce relatively more organic waste.

b) Demography (difference in amount of population for example, tourist places).

c) Locations: includes abundance and type of regions natural resource, and socio-cultural factors which highly contribute for variation of waste in different areas.

d) Season: for instance during certain season's yard wastes such as grass clippings and raked leaves add greatly to solid waste (web page accessed, October 10, 2013).

Unlike various composition of solid waste in different areas, process of defining waste management practice is similar in each area i.e. by assessing waste handling processes beginning from collection, transfer to disposal present in a sample households. Conduct of waste management studies by using this method has several importances. "Some of these are: for identification of potential resource recovery activities, facilitate collection, transport and processing equipment, taking essential health, aesthetic and environmental precautions, and for monitoring changes in waste composition over time and improving waste 
management system" (Gidarkos, Havas and Ntzamilis 2005). Therefore, composition, generation, treatment practice study is cornerstone for successful planning and implementation of solid waste management.

\subsection{Processing and Recovery}

This functional element includes all techniques, equipments and facilities used both to improve the efficiency of other functional elements and to recover usable materials, conversion products, produce energy, and compost from solid wastes. In addition, it also provides several advantages. First, it can serve to reduce total volume and weight of waste material that requires collection and final disposal. Volume reduction also helps to conserve land resources since land is the ultimate sink for most waste materials. On the other side, it also reduces total transportation cost of waste to its final disposal site (Uriarte and Filemon 2008). Solid waste processing and recovery has been carried out beginning from separation and processing of wastes at the source. But, separations of mixed wastes usually occur at materials recovery facility, transfer stations, combustion facilities and disposal sites. It often includes separation of bulky items, separation of waste components by size using screens, manual separation of waste components, and separation of ferrous and non-ferrous metals. Then they enter in small and large scale industries for recovery activities. For example, organic fraction of MSW can be transformed by a variety of biological and thermal processes. The most commonly used biological transformation process is aerobic composting and, the most commonly used thermal transformation process is incineration (web page accessed, October 23, 2013).

\subsection{Disposal}

This is final functional element in SWM system. Disposal activities are associated with final dump of solid wastes directly to a landfill site. Today disposal of wastes by land filling or land spreading is the ultimate fate of all solid wastes whether they are residential wastes, or residual materials from materials recovery facilities. "However, in most developed countries this method is officially banned allowing only sanitary landfill for final disposal. Because sanitary landfill is not a dump it is an engineered facility used for disposing of solid wastes on land without creating nuisances or hazards to public health and environment" (Techobanglous 2002). "Though it is the most common technology around the world, conventional and environmental unfriendly methods such as open-burning, open-dumping, and non-sanitary landfill can still be used as disposal method" (UNEP 2009).

\subsection{Incineration}

Incineration is one option for sustainable solid waste management. It is defined as the process of burning solid waste under controlled conditions to reduce weight and volume of solid waste, and often to produce energy. This process is really waste reduction, not waste disposal, though following incineration ash must still be disposed. It is recognized as a practical method of disposing of certain hazardous waste materials (such as medical waste). Incineration can be carried out both on a small scale by individuals and on a large scale by industry. This facility does not require much area so that it is common in countries like Japan where land is scarce (web page accessed, September 5, 2010).

Generally, according to (UNEP 1996) there are considerations that we should keep in our mind when we want to choose incineration. These are: the necessary environmental controls are properly installed and maintained; the facility is properly sized and sited to fit well with other components of the MSWM and the material to be burned is combustible and has sufficient energy content.

\subsection{Composting}

It is a process of allowing biological decomposition of solid organic materials by bacteria, fungi, worms, insects, and other organisms in to a soil for transforming large quantities of organic materials to compost (humus like materials). "The organic materials produced by composting can be added to soil to supply plant nutrients such as nitrogen, phosphorus, potassium, iron, sulfur, and calcium, slow soil erosion, make clay soils more porous or increase water holding capacity of sandy soils" (Enger and Smith, 2008).

There are three scales at which composting has been implemented; residential level, decentralized community level, and centralized and large scale municipality level. The larger the undertaking the more capital investment is required. Most developing countries which have found success with composting revealed that composting works best when implemented at household level, with some project doing well at community level as well. At municipal level financial commitment required to maintain equipment has resulted in wide spread failures (Zerbock 2003).

In cities of developing countries, most large mixed waste compost plants have failed or operate at less than $30 \%$ of capacity. The problems most often cited for such failures include: high operation and management costs, high transportation costs, poor quality of product as a result of lack of sorting (especially plastic and glass fragments), poor understanding of composting process, and high competition from chemical fertilizers (which are often subsidized) (UNEP 1996).

\subsection{Reuse and Recycle}

Reuse involves cleaning and using materials over and over. In other words, it means the use of a product more than once in its original form for the same or a new purpose. It relays on items that can be used over and over instead of throw away items. This method is used to decrease the use of matter and energy resources, cuts pollution, creates local jobs, and saves money (Miller, 2007). "Reusing is 
more efficient and better than recycling and composting methods because cleaning and reusing materials in their present form avoids the cost of energy for remaking them in to something else" (Cunningham 2008).

In addition to reuse, recycling is also an obvious treatment of solid waste problem. It is an important way of collecting solid waste materials and turning them in to useful products. Such materials can be reprocessed in two ways: primary and secondary. "Primary recycling is a process in which original waste material is made back into the same material for example, newspapers recycled to make newsprint. In secondary recycling, waste materials are made into different products that may or may not be recyclable for instance, cardboard from waste to news papers" (Miller 2007).

Recycling is both environmental and economical issue. Many people's are motivated to recycle because of environmental concern i.e. it reduces pollution, it also save energy, space and resources, helps to protect biodiversity and reduce litter. Economically, it can save money for items like paper, metals and some plastics.

\subsection{Public Participation}

Public Participation may be broadly defined as the involvement of citizens in governmental decision-making processes. This ranges from being given notice of public hearings to being actively included in decisions that affect communities. It is generally a process of engaging stakeholders so that those most likely to be impacted by a particular activity can influence the outcome. Public refers not only to private citizens but institutions, civil society, labor unions, the Government, public officials, industrial, agricultural and trade associations, scientific and professional societies, environmental, educational and Health associations and other minority Groups (EPA 2005).

It is necessary to establish the Public Involvement Framework and identify participants or stakeholders and determine their legitimacy by social analysis (UNEP 2002). There is a wide variety of models from which to choose. The one chosen should reflect the public input required. Some models of public participation are given below.

\subsubsection{The Exclusionary Model}

This model indicates that the government or agency is the exclusive guardian of the people and any self-acclaimed representative of the public interest was an officious meddler. Only competitors and other institutional stakeholders were allowed to participate. This proved inappropriate for riskoriented decision-making. There may be some usefulness in cases of rate hearings and public utility regulation. (Mc. Garity 2005) In the Caribbean, some decision-makers adopt an approach that they have been appointed or selected to make decisions for the populations who may not have the knowledge and information to make decisions for themselves.

\subsubsection{The Confrontational Model}

The Confrontational Model is at the other end of the spectrum to the Exclusionary Model and results from a stringent application of the Exclusionary Model. This is really not a desirable model. It is not effective in addressing matters of intense local interest but may be effective if activists can attract the sympathy of a large number of other inactive members of public. It is a way of keeping certain topics or concerns on the public agenda or getting agencies to revisit decisions already made.

When a person feels excluded or that her/his interest has not been well represented she/he can confront the agency. Sometimes there is picketing and civil disobedience e.g. in the 1980s, outraged neighbors picketed for proposed hazardous waste dumps. Also there have been shouting matches at meetings during debates on SW disposal sites or incinerators or other SWMP components being located near their homes and offices.

Confrontations are usually intended to be very public but they are not designed to be participatory and certainly are not conducive to informed dialogue about risks and mitigation. Sometimes a decision-maker agrees to speak to the activists to induce them to stop their action but they are rarely asked to participate in the actual decision-making process. This model is characterized by distrust and is restricted to local activities and usually employed by individuals or ad hoc groups. Activists, who at times participate at considerable risk to their own economic and physical well-being, seek a wider audience. Only highly emotional matters or matters of high principle are likely to justify such individual action. Purely economic interests do not often invoke the confrontational model. (Mc. Garity 2005)

\subsubsection{The Adversarial Model}

The Adversarial Model represents a situation where all interested groups have a right to participate by submitting facts, evidence, views and arguments. The agency assumes the role of neutral decision-maker. Based on courtroom adjudication, parties who may be represented by counsel are usually allowed testimony through experts. This is dominated by lawyers and the settlement presumes winners and losers. (Mc. Garity 2005) This model was experienced in cases where residents sought compensation from a Caribbean government in court for the health effects from an existing LF. In some cases, this is a slow and expensive process. In some cases, protesters to the location of a LF seek international attention. This can be a cheaper and more effective approach.

\subsubsection{The Due Consideration Model}

The Due Consideration Model is similar to the adversarial model except that the agency takes a position prior to the public hearing and invites the public to comment on their decision as well as on the issues generally. It does not adopt the procedural protection of the Adversarial Model and so is less burdensome. The agency is only required to give due consideration of outsiders and explain its chosen action. This model is better adapted to issues that are policy dominated and for which factual accuracy is not essential. Participants are less directly involved in the actual decision making process. Suspicions are easily raised that due consideration is 
not given to participants points of view especially when the agency adopts the option it initially proposed with little or no adjustment (Mc. Garity 2005).

\subsubsection{The Mediation Model}

The Mediation Model requires that representatives of groups meet together, often with the aid of a mediator or facilitator, to present facts and arguments so as to reach an agreement on the ultimate result. The agency may participate in the discussions and attempt to implement agreed solutions. Public participation may be invited at this stage while Negotiators meet until agreement is reached. This may be a useful approach in planning SWMPs as the relationship between government and residents is often confrontational. (Mc. Garity 2005)

\subsubsection{The Advisory Committee Model}

The Advisory Committee Model is similar to Mediation Model except that it relies heavily on scientific and technological expertise. The Agency appoints a committee of disinterested experts to advise on the technical issues and on a decision. This model seems favored by decision makers who are not scientifically trained and who do not want to "take the heat". Agency may lose control of the outcome but this may be reduced by choosing experts for the advisory committee whose views on technical issues will yield results that are in accordance with the decision-maker's policy preferences.

\subsection{Measuring Success in Public Participation}

Elizabeth Evans, in her paper presented at the International Association for Public Participation (IAP) in 2002, sought to address how the success of the Public Participation Process could be determined. Her paper explores the question of evaluation of consultation processes and how these may be approached. She focused on three issues:

1) What is meant by success in the context of Public Participation?

2) Whether there are meaningful consistent ways of measuring success

3) Whether it is wise to attempt such measurement (Evans 2002).

The practice of Public Participation is complex. It may be considered as a process that contributes to overall results of the business or enterprise. While it is not new, emphasis over the past five years has been on selling the idea to decisionmakers that Public Participation would add value and reduce costs and risks. The problem with "success" is that those involved are likely to have different ideas of what success means. The process of Public Participation requires the invitation of stakeholders to participate and there is a need to identify: The range of stakeholders; the inputs required (financial and other resources) in information staff, training, policy etc.; processes (nuts and bolts of the programme); and outputs (products and deliverables that come out of the work done) (Evans 2002).

The range of activities that make up Public Participation is expanding rapidly and references are made to community engagement to build good will. Community participation can be a wide range of activities especially in SWM and it takes account of aspirations and views of people directly affected. It facilitates involvement of affected communities, businesses, etc. through discussions, debates, negotiations and planning. (Evans 2002) based measurement of success on four core values and associated principles previously articulated by the International Association of Public Participation (IAP) as follows:

1. Equity - decision-makers should provide opportunities for all those with an interest in the subject

2. Integrity - decision-makers must act in good faith

3. Openness - provision of information to the public that is accurate, honest, comprehensive, clear and accessible

4. Accountability - specification of the degree to which public involvement would influence decision making and accurate reports on how commitments are discharged.

\subsection{Some Best Practices for Successful Public Involvement}

UNEP (2002) proposed a list of best practices as follows: (1) Develop a public involvement framework as early as possible to establish the scope, timing and resource requirements necessary to support the process; (2) Identify the participants and stakeholders and establish their legitimacy and "representativeness" (using social analysis). It should be noted that not all social actors can or should be consulted on every detail of the proposed project; (3) Identify appropriate techniques of public participation/communication and provide relevant information in a form which can be easily understood (e.g. using a combination of seminars, simple written materials, visual aids and scale models can help to make the technical material accessible to the nonspecialist); (4) Plan and execute events at a time and venue that will encourage the maximum attendance and free exchange of views by all interested groups. Money may be specifically allocated to help facilitate community involvement (e.g. to pay for travelling expenses or costs involved in hosting meetings and inquiries); (5) Allow stakeholders sufficient time to assimilate the information provided, consider the implications and present their views; (6) Identify mechanisms which ensure decision makers consider views and suggestions made by stakeholders integrate findings and recommendations into the environmental assessment report, financing proposal and agreement; and (7) Ensure that responses and feedback are given on issues or concerns raised. The best practices are quite representative of the methods outlined by other commentators and form the basis on which the performance evaluation of the OECS SWMP may be based.

\section{Methodology}

\subsection{Description of the Study Area}

Jigjiga, the capital city of Somali National Regional State of East Ethiopia, is about $630 \mathrm{~km}$ East from Addis Ababa City 
and $105 \mathrm{~km}$ from Harar city of East Hararge Zone of Oromia and Harari Region. The city is astronomically located between $9^{\circ} 16^{\prime} 30^{\prime \prime}$ to $9^{\circ} 24^{\prime} 30^{\prime \prime} \mathrm{N}$ Latitude and $42^{\circ} 44^{\prime} 0^{\prime \prime}$ to $42^{\circ} 51^{\prime}$ 0" E Longitude (Fig. 1). It has an elevation of 1609 meters a.m.s.l. The city hosts Jigjiga University.

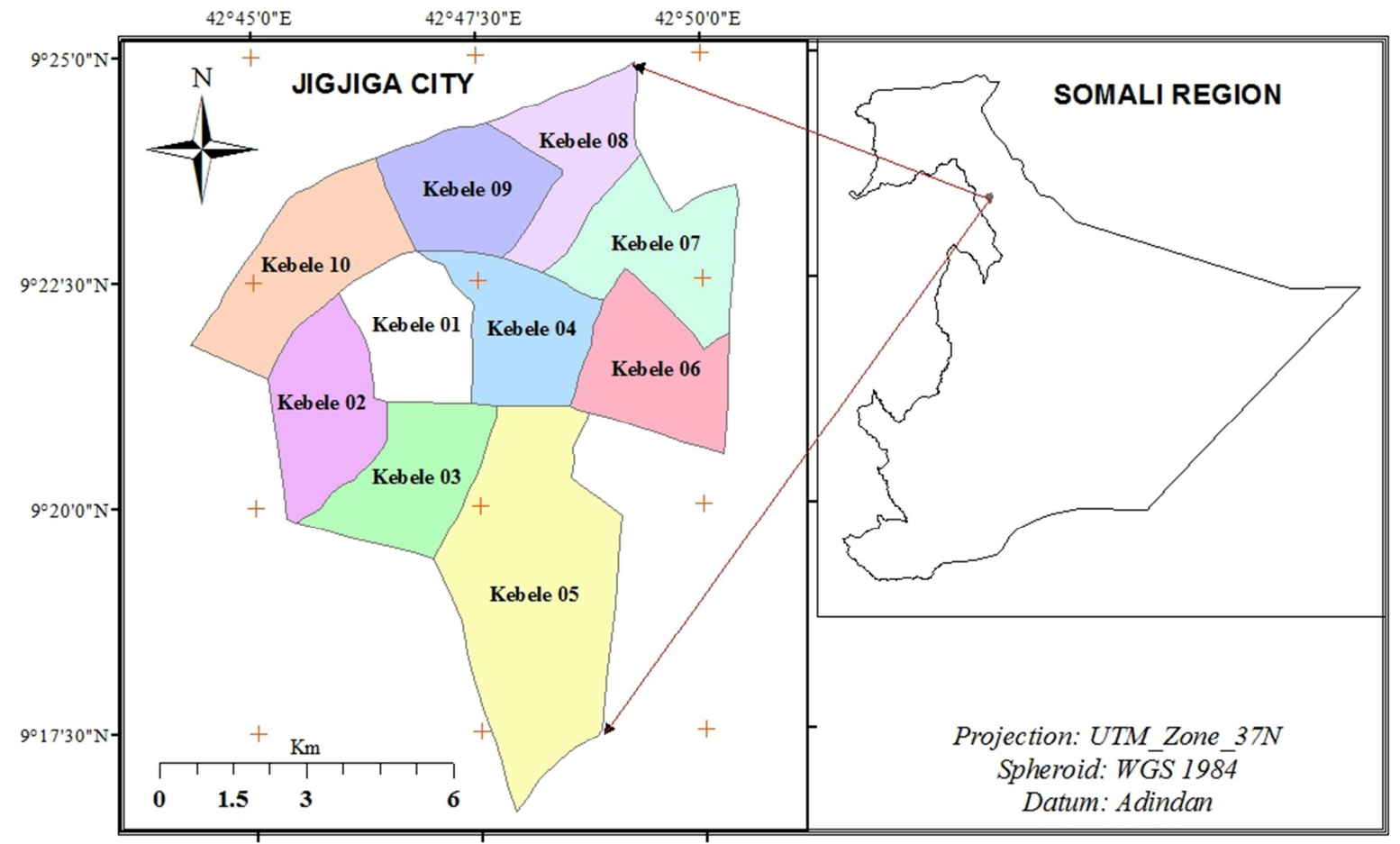

Figure 1. Location Map of Study Area.

Based on the recent (2007) census data from CSA of Ethiopia, the city has a population of 125,876 of which 67,128 were males and 58,745 were females. The total household count is about 23,263 with an average of size of 5.4 persons to a household. The 1994 census reported a total population of 56,821 . The city has recorded a population growth of $121 \%$ in 13 years. The climate of the city is subtropical, with a mean annual temperature of $19.5{ }^{\circ} \mathrm{C}$ and annual average rainfall ranging from $150 \mathrm{~mm}$ to $1000 \mathrm{~mm}$. The highest temperature is experienced between November and March and the lowest between July and September.

\subsection{Methods}

\subsubsection{Data Source and Data Type}

All required data for this study were collected both from primary and secondary sources. The primary data were collected from sampled households respondents, researchers' observation and key informants. Similarly, thorough review of all available published and unpublished documents of relevant organizations was conducted.

\subsubsection{Sampling Technique}

For this study, purposive sampling and stratified random sampling in two Kebeles (the smallest administrative unit), 03 kebele from the commercial center and 05 kebele from residential areas of the city were selected. Jigjiga city is purposively selected being the interests of the sponsor of the research. Stratified sampling technique was used due to the variability of the municipal solid waste generation sources.
Heterogeneous units were divided into non-overlapping groups resulting in representative sampling. The numbers of samples within each stratum were determined based on respective proportional percentages of each stratum. In this study, to identify the participating households, they were stratified into two groups; residential and non- residential (commercial) categorized as $74 \%$ and $26 \%$ of total number of housing units, respectively, CSA (2007). Sample size (n) of households that participate was determined by using a sample technique (Cochran, 1977) formula, given by:

$$
n=\frac{N Z^{2} P Q}{d^{2}(N-1)+Z^{2} P Q}
$$

Where;

$\mathrm{P}=$ Housing unit variable (Residential houses which is $74 \%$ of $\mathrm{N}$ )

$\mathrm{Q}=1-\mathrm{P}$ (Non residential houses which is $26 \%$ of $\mathrm{N}$ )

$\mathrm{N}=$ Total number of housing units $(23,263$; CSA, 2007)

$\mathrm{Z}=$ Standardized normal variable and valued that corresponds to $95 \%$ confidence interval equal to 1.96

$\mathrm{d}=$ Allowable error $(0.05)$

Therefore, the result, $\mathrm{n}=293$ was the minimum reliable sample size of housing units while five housing units were added to augment the confidence. This was done in the two selected Kebeles and the total sample size was 298 households. After this, simple random sampling was employed based on the proportional percentage of samples within each stratum to decide the number of samples that was taken from each stratum as summarized in table 1. 
Table 1. Sample Selection with proportional allocation.

\begin{tabular}{lllll}
\hline No. & Kebele & $\begin{array}{l}\text { Number of } \\
\text { households }\end{array}$ & $\begin{array}{l}\text { Proportional } \\
\text { percentage }\end{array}$ & $\begin{array}{l}\text { Sample } \\
\text { size }\end{array}$ \\
\hline 1 & 03 kebele & 678 & $12.2 \%$ & 36 \\
2 & 05 kebele & 4899 & $87.8 \%$ & 262 \\
Total & & 5077 & $100 \%$ & 298 \\
\hline
\end{tabular}

Source: Own Computation based on CSA, 2007 data

As showed in the table above, in 03 kebele there are about 678 households out of which 36 households samples were taken proportionally (10 households residential and 26 households commercial centers). Similarly, from 05 kebele out of about 4399 total households, 262 households samples were considered (of which 230 households were residential and 32 households were commercial centers).

\subsubsection{Data Collection and Analysis}

The data collection was done using checklists which were pre-tested prior to the actual field work. The bulk of the data generated for this study were qualitative. Structured questionnaire, interview guideline and field observation were used to obtain data and information for the study. The structured questionnaire was used for the selected households to have information about their sources of energy, housing conditions, onsite solid waste handling, solid waste disposal practices and other activities. Beside this, checklist was also provided for the city government's Sanitation and Beautification Department (SBD) and Hormud SWM Company to gather information on their current solid waste management. Collection of information about solid waste treatment and the role of community participation from the studied households was extended for eight consecutive days. The collection was done by two trained collectors. Equipments like digital camera and GPS were used for photographing and ground control points by the researchers during field observations. Waste Collection sites where containers are placed, market places where waste handling is expected to be difficult and open dumping sites, were also purposely used as sample units to collect qualitative information. The data were analyzed combining the information collected from secondary sources, qualitative and quantitative survey.

\section{Result and Discussion}

\subsection{Solid Waste Composition}

The result of the survey in the study area showed that municipal waste is an aggregate of all substances ready for disposal. The composition of the solid organic waste was almost homogenous in nature across the study households. As it was observed in this study, majority of the waste was of plastic origin while the animal and the industrial origin was almost none in most of the households. Of the plastic source, residues of festal (known locally as Mika) and liquid containers take the greatest portion. Overall composition includes paper, vegetable peelings, onion seed coats, broken plastic and festal, soil and dust, animal dung, grasses, used shoes, pieces of cloth, small bottles, soot, etc. The waste aggregate more frequent in the whole mass of household waste was house sweeping, which is composed of soil and dust followed by pieces of paper and vegetable peelings (plates 1).

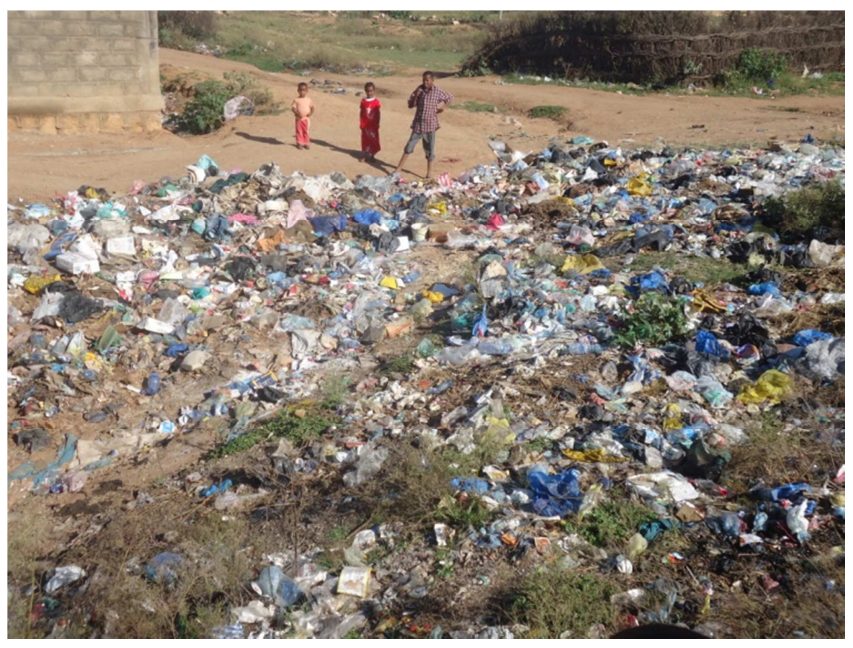

Photo by Researchers, 15 October, 2013

Plate 1. Open Dumpsite nearby Dr. Abdulmajid TTC.

It can be observed from plates 1 and 2 that ash swept out from kitchens and chatt remnant (sticks and leaves) is more in quantity than other waste. However, it is not removed every day. When considering the solid waste production across different sources (residential and commercial, in this study), the residential origin was found to be higher (74\%) while the remaining $(26 \%)$ accounts for commercial and other origin.

\subsection{Solid Waste Generation Rates}

With regard to solid waste generation rate, even though the solid waste trend is expected to increase in general, recent and up to date data were not available. However, as per the data obtained from Hormud SWM Company, about 3150 sacks of waste each weighting from $20 \mathrm{~kg}$ to $30 \mathrm{~kg}$ were collected every day from about 2950 households. Computation result shows that the average waste generation rate of the city is estimated to be $26.6 \mathrm{~kg}$ /day/households in weight.

\subsection{Solid waste Source}

The result from the surveyed households reveals that MSW generation by source and type in Jigjiga City has the following distribution (Fig. 1). The composition of municipal waste varies greatly from country to country and changes significantly with time. Waste can be classified into several types. However, the following list represents a typical classification of municipal solid wastes: (1) Biodegradable waste: (like; food and kitchen waste, green waste, paper), (2) Recyclable material: (paper, glass, bottles, metals, certain plastics, batteries etc.) and (3) medical wastes. 

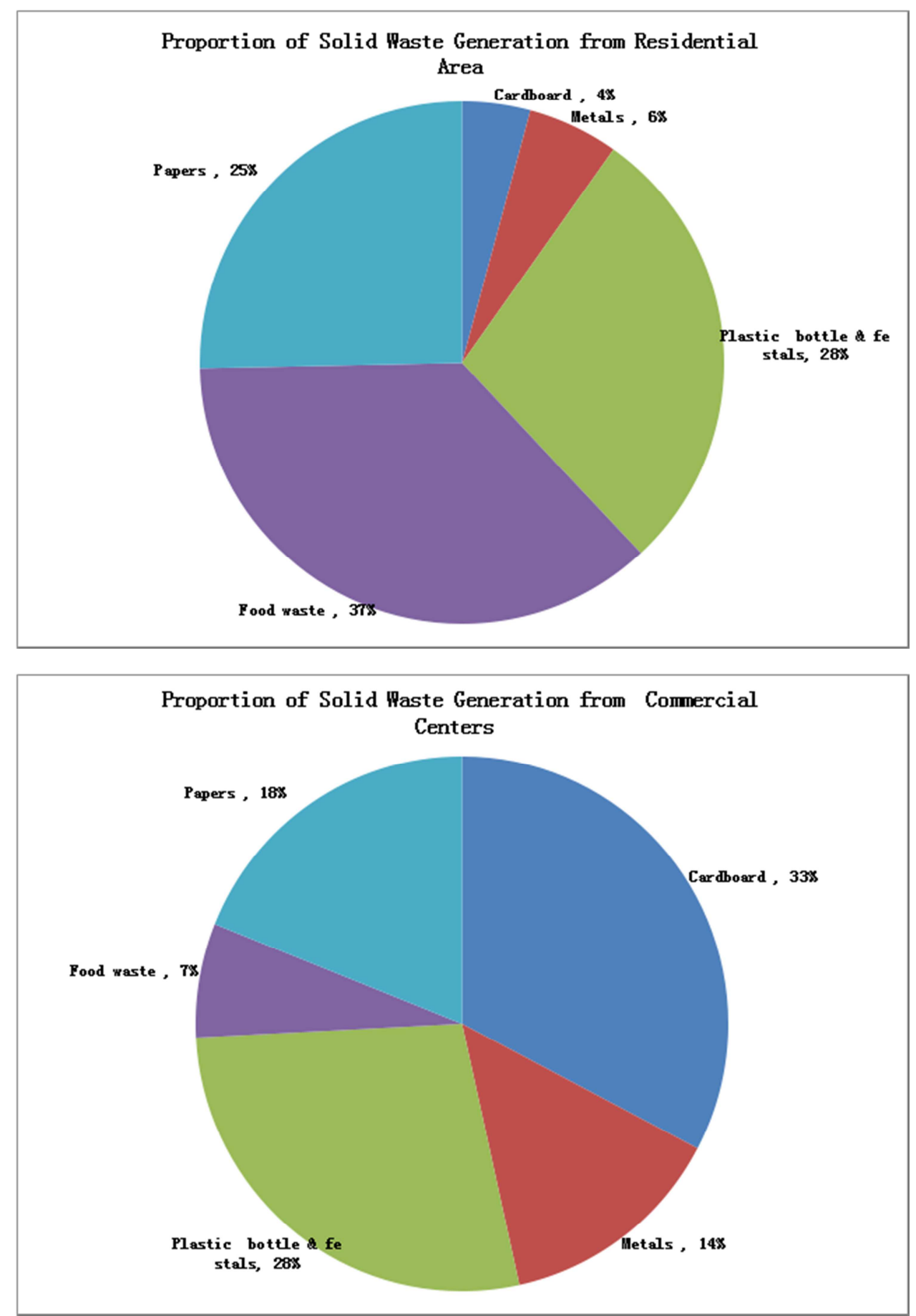

Source: A survey conducted by researchers

Figure 2. Municipal solid waste generation by source and type of Jigiiga City.

Fig. 2 shows percentage of municipal solid waste generations by source and type in Jigjiga City. It has been revealed that the largest constituent of residential solid waste is food-waste be $37 \%$ and followed by plastic bottles $\&$ bags $28 \%$, papers $25 \%$ and the remaining $6 \%$ and $4 \%$ are metals and cardboards, respectively. The situation is reverse in the case commercial area's waste composition as the highest constituent is cardboard $33 \%$ and the least is food- waste $7 \%$.

However, if we see the wastes from the recycling point of view, many of the constituents are compostable and recyclable materials, and hence it indicates that recycling practices are effective SWM practice. Unfortunately, it was so far not practiced in the city, and this is why we see a lot of paper and plastic substances thrown out in river banks, ditches and open areas plate 2 . 

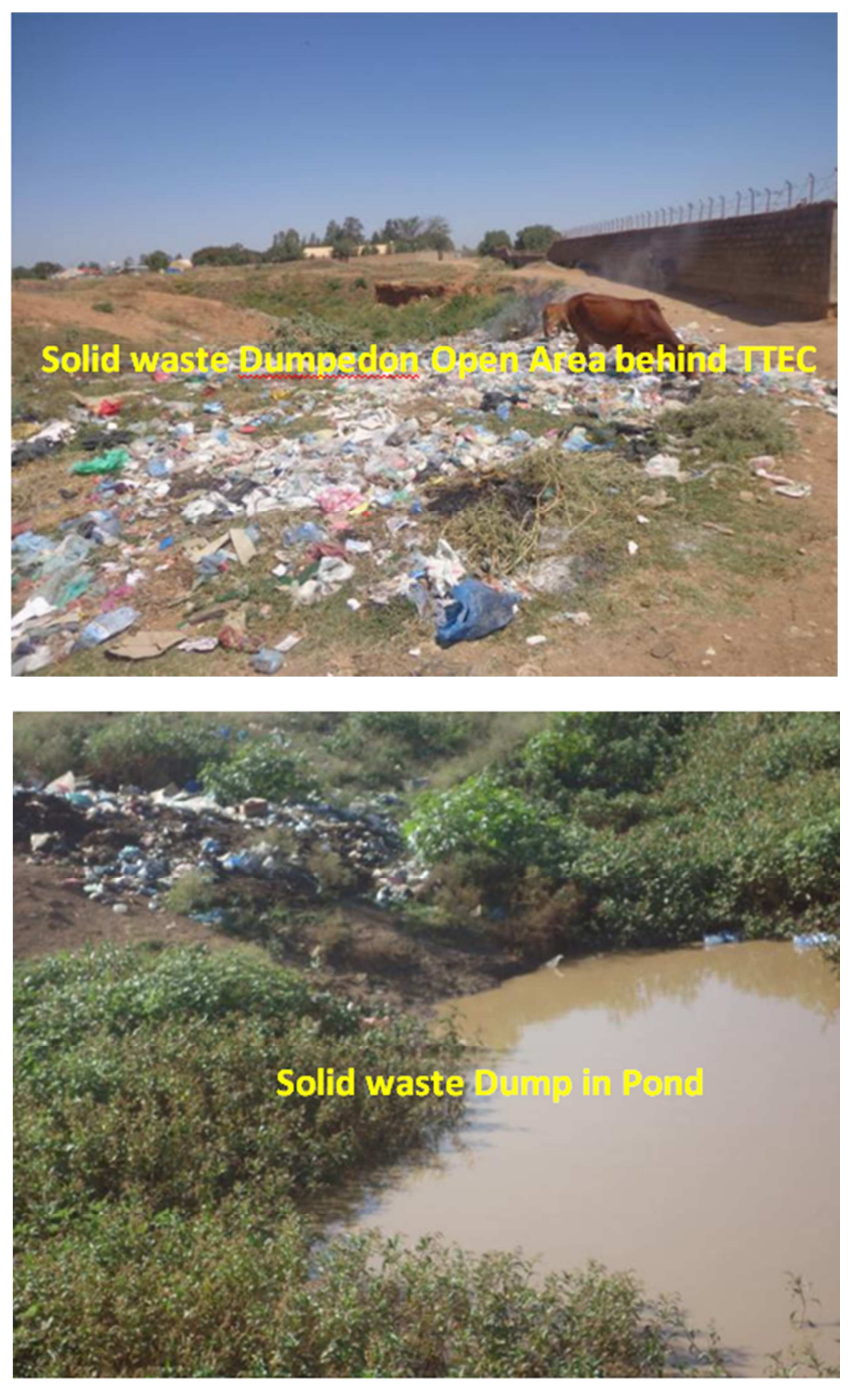

Photo by: Researchers 20 October, 2013

Plate 2. Waste substances thrown out in unauthorized areas in Jigjiga City.

\subsection{Existing Solid Waste Management Practices}

The management of Jigjiga City waste is a history of institutional trials and abandonment, with most issues remaining unsolved. The new established authorized organization on the sector, sanitation and beautification department (SBD) at the city government level was assigned the responsibility for the management in 2008. The assignment came as a result of the failure of previous authorities-the Ministry of Health and Sanitation, and the private sector to effectively manage City's solid wastes. Unfortunately, the SBD is also struggling with tight budgets, lack of qualified manpower, and experience in waste management. Uncommon to most other cities of the country, Jigjiga City waste management practice is engaged by a legalized private organization called Hormud SWM Company.

\subsubsection{On Site Handling}

A proper waste handling at household level has positive implication on waste management. The responsibility of household waste handling also varies between the residential and the commercial. In residential households female members of the family are responsible to handle the households cleaning and separating of the waste. The male members of the family do not participate in these activities, except at times they engage themselves when the waste is bulky and some physical help is required to transport it to dumping places. In case of the commercial areas, it is servants who collect and dispose of households wastes.

\subsubsection{Sorting}

Sorting is an essential component of solid waste management. It is a kind of activity which is separating different types of wastes in their respective nature. It makes waste management easy and simple. However, it should not be a onetime activity, rather should be a habit for proper and sustainable solid waste management. Separating different types of waste components helps to sort recyclable materials from non recyclable and identify decomposable (organic) materials from non decomposable. The process is also efficient in reducing the problem of landfill sites and expenses. However, as to the respondents, there is no/little separation of solid wastes in Jigjiga Town whereby over $92 \%$ of the households, invariably confirmed the absence of solid wastes separation practices during both collection and disposal periods. The remaining few households or $8 \%$ of the respondents replied that solid wastes were sorted into organic and inorganic wastes. Inorganic wastes like cans are usually sorted for sale. In few households, organic wastes like plant origin are sorted for the purpose of reusing in their gardens and as fuel after the waste gets dried; this is seen in residential households. Animal source (meat and bone) is used to feed domestic animals like dogs. Some households give the waste away to their neighbors who use it for different purpose like for animal feed. The purpose of separated waste is different for different surveyed households (Fig. 3).

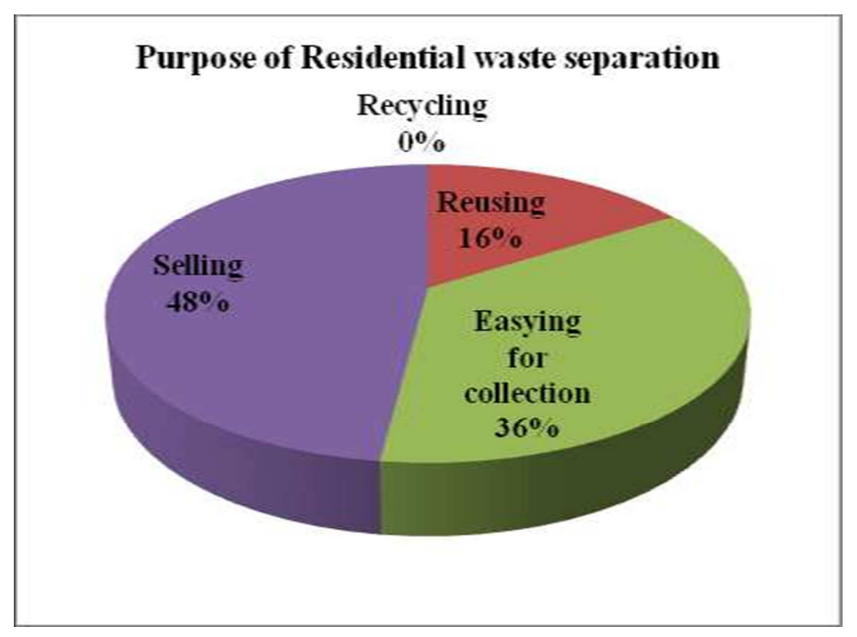

Figure 3. Purposes of waste separation in Jigjiga Town.

Figure 3 clearly shows that from residential households, $48 \%$ of solid wastes are separately collected for selling, $36 \%$ for easing collection and $16 \%$ for reusing purposes. 
Unfortunately, there is no solid waste collected separately for the purpose of recycling in Jigjiga City. This indicates that even if a great deal of recyclable solid wastes is generated in the city, it is not drawn to the attention anybody for the purpose of recycling. Absence of information from commercial households implies the solid wastes are indiscriminately collected in the area.

\subsubsection{Composting}

With regard to composting, the households practicing composting are very few, while a significant amount of this refuse is largely of plant origin /biodegradable/ organic waste. (Gardner 2001) and (Bezaye 2008), argued that composting is an ancient practice where more cities in the world nowadays are reclaiming the benefits of reusing solid organic waste material. It is a natural way to prepare the waste for reuse. During the study, it was observed that there are people who know at least the use of organic waste for soil fertility improvement. There are also some people who have training in composting, but are not practicing. The major limitation for not practicing compost as indicated by the respondent is lack of market and a piece of land for urban agriculture.

The key respondents were interviewed whether incineration has been practiced at secured places or not. Accordingly, as the informants, practice of incineration at secured places is confined to health institutions typically to manage medical wastes even though the practice takes place only sometimes. So far, no incineration taking place in or near the compound of households.

\subsubsection{Waste Reuse}

Reuse is an important factor to reduce the amount of waste to be dumped at the final disposal site. The study result indicates that there is little practice of waste reuse for different purposes like industrial waste like can for sale, plant origin waste for fuel, animal source (meat and bone) waste for domestic animals feed.

In general, as far as waste reuse is concerned, there is no formal practice in the city except some people called "Korales" who move through the city to buy recyclable items such as glass, plastic, tin cans, metals, shoes etc. from different houses, hotels, restaurants, repairs services and sell them to small recyclers and industries. There are also people engaged in similar types of job known locally as "Liwach" who go around the city and exchange used clothes and shoes with new household utensils and sell them to low-income people

\subsubsection{Collection}

Waste collection service is one of the chief components of municipal SWM practices. The survey showed that containers are placed in some neighborhoods. However, a number of containers are not enough with respect to waste generated and a portion of the neighborhoods are obliged to throw their refuse into an open area. Some of the households, who are not enjoying municipal services, have their own way of household waste disposal. The tools that are used for solid waste collection in both residential and commercial area are shown below in table 2 .

Table 2. Number of respondents for solid waste primary collection Tools in Jigjiga City.

\begin{tabular}{llllll}
\hline \multirow{2}{*}{ No } & \multirow{2}{*}{ Tools } & Number & & Percent (\%) & \\
\cline { 3 - 6 } & & Residential & Commercial & Residential & Commercial \\
\hline 1 & Metallic container & 0 & 0 & $0 \%$ & $0 \%$ \\
2 & Basket & 2 & 5 & $0.83 \%$ & $8.6 \%$ \\
3 & Plastic bag & 0 & 0 & $0 \%$ & $0 \%$ \\
4 & Cardboard & 0 & 0 & $0 \%$ & $0 \%$ \\
5 & Empty sack & 238 & 53 & $99.1 \%$ & $91.4 \%$ \\
Total & & 240 & 58 & $100 \%$ & $100 \%$ \\
\hline
\end{tabular}

During the interview, almost all of the respondents from both residential and commercial households stated that the bulk of primary waste collection equipments are sacks whereas a few said that they use baskets for this purpose. As to Hormud SWM Company, in each Kebele, strategic locations are assigned for the primary collectors (mainly micro and small scale enterprises) to make the wastes ready for the motorized further collection and disposition. Most of the areas in the city are inaccessible for motorized collection; therefore, the human powered collection system is mostly used.

Generally, there are three basic types of collection equipments. These are: human powered, animal powered, and engine powered. Under the Jigjiga City situation, both human and motorized collection equipment are being used. With regard to the human aspect, transportation of wastes to the containers is possible using hands and hand pushed carts.

The current trend of storage bins reveals in the city of Jigjiga that dust bins are located nowhere on main roads. For temporary storage, households prepare different types of receptacles such as baskets, card boxes, cans, plastic bags, barrels, etc. Only $65 \%$ of the MSW generated in Jigjiga City is collected and disposed off by the Hormud SWM Company in the Shiek Aligure Open Dumpsite, with no recycled and a little composted. The rest about $35 \%$ is dumped in uncontrolled environment like on/in streets, empty spaces, and river banks.

There are different waste collection services given in the study area. Of these services, the majority use door-to-door collection services while others don't receive any services rather they dispose wastes into river systems, burn and reuse for their gardens even though they didn't mention.

As far as waste transfer in concerned, Hormud SWM Company's trucks are solely used to transfer wastes from the source to the destination. The interview with the company's manager reveals that the trucks collect wastes every day from commercial centers and every week from residential households (table 3). 
Table 3. The frequency of solid wastes collection and transfer to the junk region.

\begin{tabular}{|c|c|c|c|c|c|}
\hline \multirow{3}{*}{ No } & \multirow{3}{*}{ Duration } & \multicolumn{4}{|c|}{ Household respondents } \\
\hline & & \multicolumn{2}{|c|}{ Number } & \multicolumn{2}{|l|}{ Percent } \\
\hline & & Residential & Commercial & Residential & Commercial \\
\hline 1 & Daily & 8 & 42 & $3.13 \%$ & $72.70 \%$ \\
\hline 2 & Weekly & 210 & 16 & $87.50 \%$ & $27.27 \%$ \\
\hline 3 & Monthly & 22 & 0 & $9.37 \%$ & $0 \%$ \\
\hline
\end{tabular}

From Table 3 it can be realized that majority of wastes from residential households are collected using door to door service weekly $(87.5 \%)$ while the rest $9.5 \%$ and $3 \%$ are done so monthly and daily, respectively. Commercial households receive the door-to-door collection system more frequently as compared with residential households the former being served $73 \%$ daily and $27 \%$ weekly. This implies that the households are determined by their bulk of waste generation to receive a better collection of solid waste services.

In Jigjiga City, there are different actors who are directly or indirectly involved in a wide range of SWM activity including Non Governmental Organizations (NGOs), private company and Micro and Small Scale Enterprises (MSSE) are the pioneers in providing door-to- door solid waste precollection service in the city. NGO (the USAID) was indirectly engaged by providing equipments to collectors who deliver the service of collecting and transporting solid waste from households to temporary collection sites (Plate $3)$.

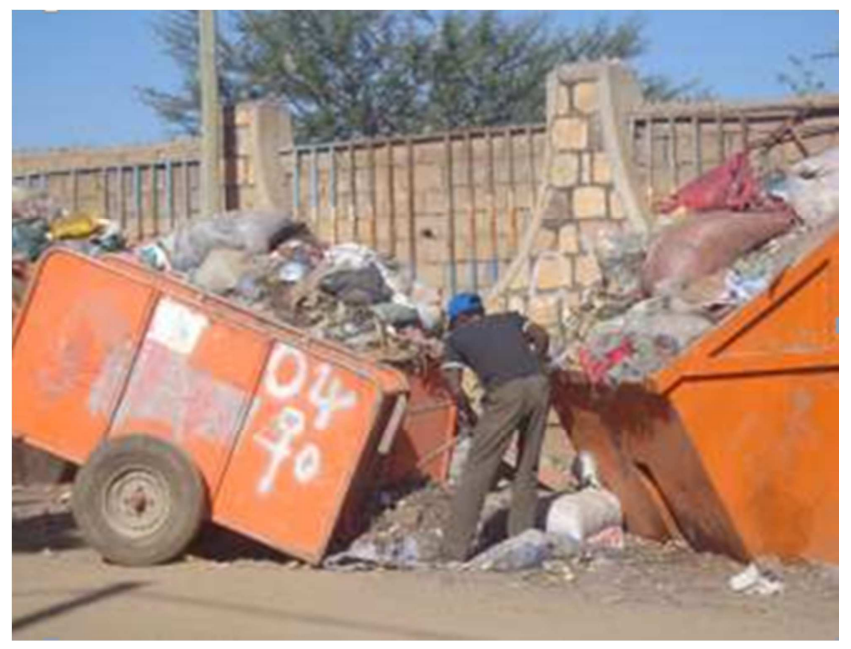

Photo by: Researchers 25 October, 2013

Plate 3. Equipments donated by USAID for temporary collection service at 04 Kebele.

The collection of waste through MSSE has provided job opportunities for many jobless youth. For instance, under the supervision of Hormud SWM Company there are 22 garbage collectors team consisting of four members each (three garbage collectors and one coordinator). The three garbage collectors are paid of 1000 birr per month while the coordinators are paid of 2000 birr per month. Apart from this, four more small scale enterprises were organized by city government on municipal SWM practices. The majority operates in the commercial households to collect solid waste using door-to-door method. The private sectors have the accumulated experience on waste collection and entrepreneurship due to their close engagement in the sector. This activity was less attractive to the government officials and easily left to be done by the informal enterprises until recently. Still the government officials have not viewed the sector as one of the employment generating fields.

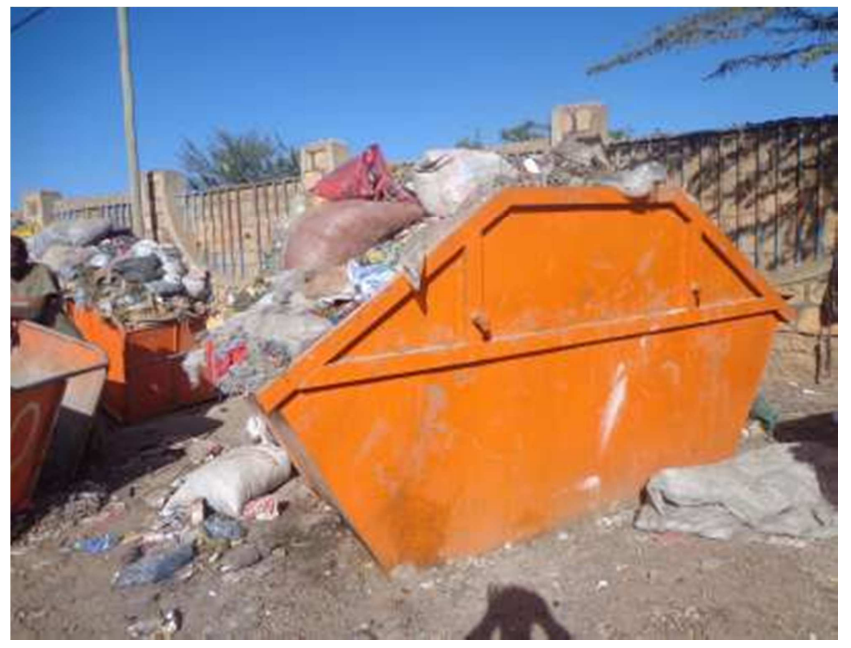

Photo by: researchers on 25 October, 2013

Plate 4. Solid wastes stayed in the containers for more than one month.

However, as to the interview result from an SBD officer of the municipality, waste collection has gradually been attracting the attentions of the officials as one of the untapped employment generating sector. Nowadays, government has pervasively been organizing private actors (specially, MSSE) and providing initial loan to become self (indirectly government) employed. The payment for the service is first done by negotiation between waste workers who are assigned for specific location and individual households in that area. However, from experience, the government realizes that the private worker collect payment from the households while the dump the waste anywhere after they collect the waste from the households. Hence nowadays, the waste is collected by the waste workers while payment for the service is collected by the authorized private company. The payment is on the bases of the waste generating sources to collection site rating 40 to 50 birr from residential households and 100 to 500 birr per from commercial centers as per the amount of solid waste 
they generate. None of the data revealed the existence of government waste workers in the study area and any other place outside of the sampled kebeles. Concerning the regularity of removal (emptiness) of containers, almost all the interviewed waste workers responded that containers did not get emptied regularly. They explained that wastes in containers are usually scattered around and remain stay in the containers over a month at times (plate 4).

Other reasons identified for the scattering of waste around the container include: the lift over height to the containers, which made it difficult for women and children to empty waste in to the container; people often have to travel more than 200 meters to reach the nearest containers which means that containers are scattered and this apparently discourages households from dumping waste in the containers. The irregularity of waste removal from the containers is affecting the health of the nearby community and the surrounding environment. The households using door-to-door collection service were asked if they had seen any improvement after receiving the service. All of the households who were using the service responded that they had seen improvement in the area of solid waste situation in their surroundings.

\subsubsection{Waste Disposal}

\section{Disposal at Transfer Station}

Waste disposal, one of the most important management practices, needs to be carefully planned. With regard to waste disposal at transfer station, the study identified that almost all solid waste generated in households is indiscriminately disposed together i.e. there is no habit of sorting organic from inorganic waste at the household level. Huge amount of organic materials comes from the rural areas depraving nutrients from the rural soil to feed the urban population, the leftovers after consumption have no way to return to the source to build the soil, rather lost and create problems to human health and the surrounding environment in the city due to mismanagement. In this study, it was observed that disposing household waste into a river system is a common practice in the study area. The result of the study also reveals that there are households who dispose the waste in to a river/ stream, drainage system and any open place. This is especially observed in the case of Gumruk open dumpsite where waste piles seemed to have adversely impacted the nearby private properties and public institutions other than public health and environmental influences. Even though the waste disposal at this transfer station has currently been stopped, the previous pile is remaining intact since the time of this survey.

Another unauthorized open dumpsite was observed at the south-western side of Dr. Abdulmajid Teacher Education College on the locality termed as $C M C$. In this dumpsite, there is surface water used by the local community for washing. The worse of these dumpsites is their extreme proximity to both residential areas and public institution at a less than ten to twenty meters (plates 5). However, until the time of the observation, solid waste has been disposed in the CMC open dumpsite while it has currently been forbidden to dispose in the Gumruk open dumpsite.
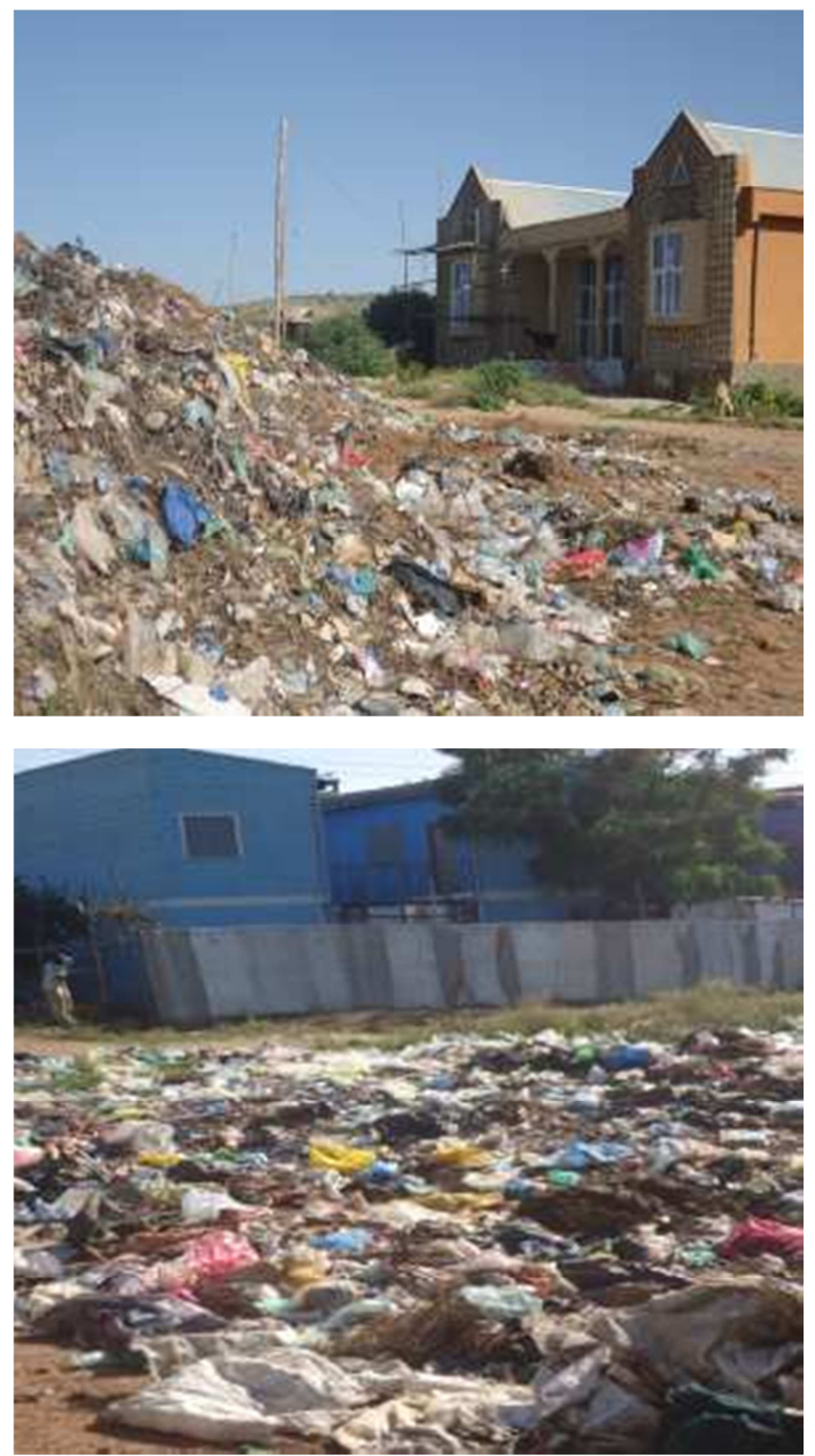

Plate 5. CMC open dumpsite and Gumruk open dumpsite.

Regarding improper waste disposal at a transfer stations, respondents blame the rarity of inspection on the waste management condition of the households, loose management action for punishment and lack of accountability of the community members. However, they didn't deny the current relatively strong monitoring due to the establishment of government structure with respect to waste management at the city government level. The respondents further stated that the decentralization of government structure at local/kebele level for more control of waste mismanagement.

As far as the punitive measure taken against the offense improper waste disposal is concerned, in contrast to the previous periods when there was neither penalty nor inspection, the monitoring is relatively strong and monetary penalty for mismanagement of wastes is imposed these days. As to the respondent the punishment amount being is small not exceeding 40-50 birr a few households preferred 
paying to carrying waste to transfer station a bit away.

On the other hand, the survey showed that nobody care about the waste dumped in the river banks. Some of the waste is taken away by the river water during rainy season while the rest remains piled in the river gorge and on its banks.

Despite the punishment on individuals who dispose waste in unauthorized places, the regulations are seemed not obeyed at all by the households. This is especially pertinent to case of institution like hotels, restaurants and business institution owners. This is because business man only runs after his/her benefit since whatsoever amount of waste he/she dump anywhere, the punishment is less amount of money. This is much less than the payment they pay for pre collectors which could be one birr for informal private individuals. This, in other way round, implies punitive measure alone does not bring a significant change unless coupled with conscious community participation.

Regarding the final disposal site, currently there is one open dumpsite known as "Shiek Aligure" which serves as final disposal site in south- west part of the city located $6 \mathrm{kms}$ away from the city center. It has a surface area of about 5 hectares. The present method of disposal is crude open dumping hauling the wastes by trucks of Hormud SWM Company (plate 6).

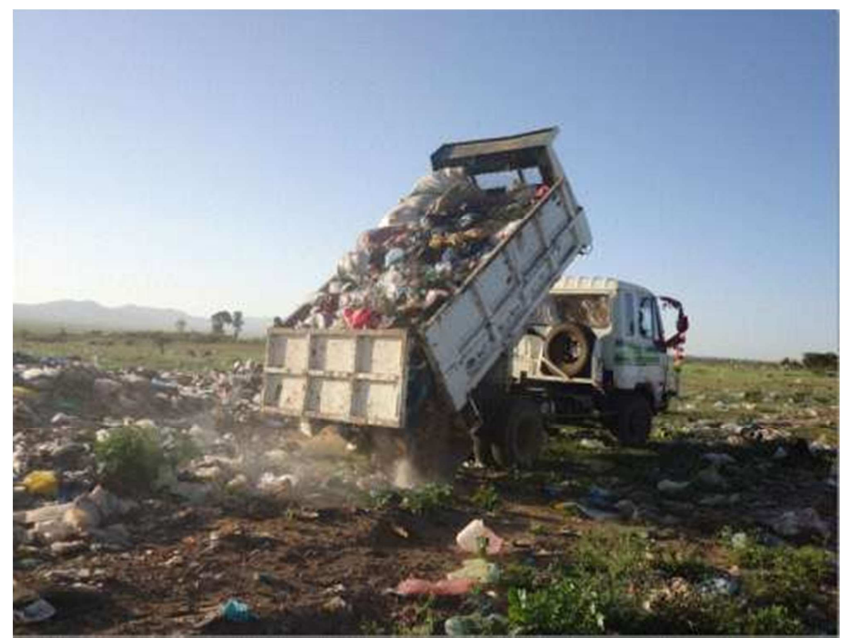

Photo by: Researchers on 25 October, 2013

Plate 6. Hormud truck hauling solid waste at "Shiek Aligure" Open Dumpsite.

The major problems associated with the disposal site are: absence of spreading and leveling by bulldozer and compacting by compactor. As the result, a great deal of festal and paper origin wastes has been blowing back to the city by wind power.

Interview at "Shiek Aligure" Dumpsite

The researchers interviewed a household which is located nearby the dumpsite. Regarding the impact of waste being disposed at this site, respondents stated that "We have been suffering from horrible increasing smell from the dumpsite that you can notice now. Smoke hardly stops; even though it stops, we are obliged to live in unsightly place and unpleasant smell. We always fear the wind-blown fire hazards to happen on our properties and lives of children. We are living here because we have no option. Even if we request everybody who may help us, nobody has drawn attention so far to us to solve the problem".

The researchers also observed the following technical and social problems: The site is established on the open grazing land nearby urban peripheral residences. The site is characterized by lack of the following basic technical features: leachate treatment, odor or vector control, rainwater drain-off, and fencing. The area is unprotected for children, women, domestic animals and scavengers reach. Socially, it is unsafe as many human scavengers work continuously and obviously living nearby the site and interfering work operation at the site for collection of materials such as wood, scrap metals and discarded food. All of waste collected from the city is dumped in this single place without separation of even organic waste. The total area of the dumpsite and beyond is covered by smoke from the continuous burning of the dumped waste due to internal ignition by the waste itself (plate 7).

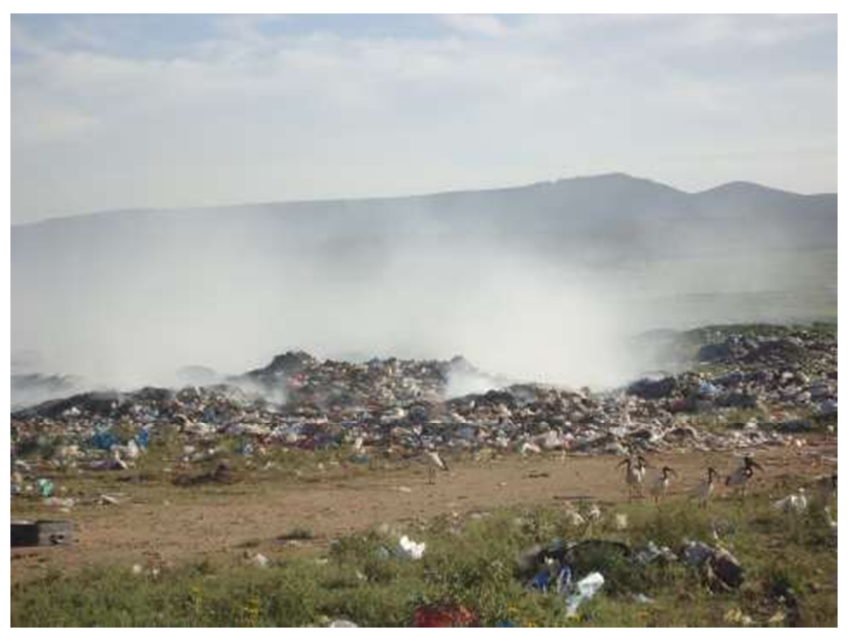

Photo by: Researchers on 15 October, 2013

Plate 7. Continuous smoking from Shiek Aligure Dumpsite.

Due to the indiscriminate disposal of waste in the area, the organic waste that goes to this dumpsite not only pollutes the land and water but also contributes to global warming by producing green house gases like methane if it is remain left untreated. The dumpsite being located on the intermittent stream, the catapult of polluted water flowing from waste disposal area can obviously inject hazards to livestock and people living in the lower basin of the stream.

As far as solid waste transportation is concerned, Hormud SWM Company is responsible for transporting wastes from each kebele to the final dumpsite "Skiek Aligure" by means of trucks. According to the interview held with the company, the main challenge in this regard includes renting cost of trucks and imbalanced communities' willingness and capability to pay for the waste disposal service.

\subsection{Role of Community Participation}

Community participation in SWM encompasses several 
forms of local involvement, including: awareness and teaching proper sanitary behavior; contributing cash, goods or labor; participating in consultation, administration, and/or management functions.

Community- based waste management (CBWM) projects require institutional support and recognition in order to be successful. An integrated system including waste separation at the source, resource recovery, and composting of organic waste requires representation of waste pickers, and integration of the community to work with allied stakeholders, including representatives of waste pickers. Local leaders are often active in management of the service or maintain close contact with the municipality or community management body. Women and teens can play crucial roles, such as initiators, managers, operators, political activists, educators, and watchdogs for the community.

Public awareness and attitudes to waste can affect the whole municipal SWM system. All steps in municipal SWM starting from household waste storage, to waste segregation, recycling, collection frequency, willingness to pay for waste management services, and opposition to siting of waste treatment and disposal facilities depend on public awareness and participation. Thus, lack of public awareness and school education about the importance of proper SWM for health and well-being of people severely restricts use of community based approaches in developing countries and also crucial factor for failure of a MSWM service in developing countries (Zurbrugg 2003) in similar way the community participation in Jigjiga town is very less. The mobilization of communities was done through the local authorities and existing community leadership structures. The identified people formed themselves into either community based organization (CBOs) which are groups formed with in a local community or micro enterprises (MEs), which are defined as a service delivery or production business, usually low capital intensive consisting of an individual or up to about 20 person, either registered or operating informally in an area. These have proper leadership structures where gender equality was greatly encouraged to ensure that women take up positions of leadership.

\section{Conclusion and Recommendation}

\subsection{Conclusion}

SWM is one of the important compulsory functions of not only urban local authorities but also of rural local bodies. However, this essential service is not efficiently and properly performed by the concerned bodies of Jigjiga City resulting in sanitation, social and environmental problems. Waste management problem is complex because it involves a multitude of scientific, technical, economic and social factors. Similarly, it is observed that lack of financial resources, institutional weakness, improper selection of technology, transportation systems and disposal options, social problem associated with lethargy towards environmental cleanliness and sanitation have made this service unsatisfactory and inefficient in the study area.

\subsection{Recommendations}

Though there is no single readymade solution to control the waste problems, the researchers found it important to indicate issues requiring serious attention of concerned bodies. The data on generation rate and the percentage contribution of each solid waste source might have changed through time due to the change in demographic and socio-economic conditions of the residencies. Therefore, further study is needed to generate more valid data for current and future planning. Due to the complexity of the situation, cooperation among different parties/citizens should be methods of choice and industries and individuals should work as partners rather than adversary to find a long-term sustainable SWM system. The estimates indicate that over $75 \%$ of the refuse from most households is largely vegetable, biodegradable organic waste which has a potential for replacing inorganic fertilizer to save foreign exchanges earning, also strengthening and implying rural-urban-linkage.

Composting has to also be promoted by all actors who have the concern in poverty alleviation's and environmental protection. Therefore, attention should be given to reusable household wastes. Land filling site selection requires special attention; standard measures should be exercised to control contamination of surface and ground water as well as air. However, none of these practices are apparent in Jigjiga City. Being reluctant on the issue needs accountability for environmental cost/ pollution cost of water resource contamination from open dump site/, cost of closing many old dumpsites and developing a new one know and then. The existing open dumpsite is environmentally unsound and socially unaccepted.

Therefore, new landfill site is urgently needed with proper selection of the site/ environmental impact assessment and construction. Waste needs proper management. The first priority should be to segregation of wastes, preferably at the point of generation, into re-usable and non-reusable for waste reduction and changing in to financially viable material; hazardous and non-hazardous components for avoidance of hazardous containing products and waste workers safety.

Based on the research findings, the integrated SWM system which combines a range of solid waste treatment options like reusing, recycling, composting, and waste to energy transformation is recommended. Majority of the households' respondents lack awareness about the proper SWM systems. Therefore, community based waste management system should be in place to ensure sustainable and efficient alleviation from challenges of waste management.

\section{Acknowledgements}

We are grateful to Jigjiga University and SERDO for providing financial support. Our sincere thanks also goes to the Jigjiga City Administration's Sanitation and Beautification Department for unreserved cooperation to 
give pieces of information during data collection.

\section{References}

[1] Allende, R., 2009. Waste history in the Gambia. Thesis (MSC), University of the Gambia.

[2] Benti Getahun 2007. Jigjiga City: Migration and the Making of a Multiethnic Metropolis. Trenton, NJ: Red Sea Press.

[3] CSA 2007. Population and housing census of Ethiopia result for Somali region.

[4] Cochran, G. 1977. Sampling Techniques, 3rd edition, Wiley Series in Productivity and Applied Mathematical Statistics. New York, USA.

[5] Evans, E. 2002. "Measuring Success in Public Participation". International Association for Public Participation Conference Paper.

[6] Issam, A. 2007. Trends and problems of solid waste management in developing countries: A case study in seven Palestinian districts. Waste Management 27 (12) 1910-1919.

[7] Javaheri, H., et al., 2006. Site Selection of municipal Solid Waste Landfills Using Analytical Hierarchical Process Method in a Geographical Information Technology Environment in Giroft. Iran Journal of Environmental Health Science Engineering. 3, 177-184.

[8] Kyessi, A. and Mwakalinga, V. 2009. GIS Application in coordinating solid waste collection: the case of Sinza neighbourhood in Kinondoni Municipality, Dar Es Salaam City, Tanzania. FIG Working Week 2009.

[9] Mc Garity, T. 2005. Article entitled "Public Participation in risk Regulation", published on the internet arts.usask.ca/policynut/courses/mcgarity.htm.

[10] Mohamed N, Elsa Z 2003. Waste Management Programme. UNIDO View Document, No. 3765. Tokyo, Japan.

[11] United Nations Environmental Programme. 2002. EIA Training Resource Manual. Section 3, "Public Involvement".

[12] WHO 1996. Guides for Municipal Solid Waste Management in Pacific countries. Health Cites, Health Islands Document Series. No. 6. World Health Organization, Western Pacific Region.

[13] World Bank 2004. Regional Guidelines on Integrated Solid Waste Management. Prepared by an International Consortium of Expert Consultants.

[14] Yami Birke 1999. Solid Waste Management in Ethiopia Integrated Development for water Supply and Sanitation. Unpublished Paper.

[15] Zerayakob Belete 2002. Analysis and Development of Solid Waste Management System of Addis Ababa City. M.Sc.Thesis Presented to the School of Graduate Studies of Jigjiga City University.

[16] Zurbrug C. 2003. Solid Waste Management in Developing Countries. Retrieved from http://www.eawag.ch/organisation/abteilungen/sandec/publika tionens-swm/downloads swm/basicsofSWM.pdf. 